\title{
Research on the Transformation of Service Capability of University Libraries in the Background of "Double First-Class" Construction
}

\author{
Wang Ting \\ Center for Ideological and Political Education, Northeast Normal University, Changchun, P.R.China
}

\section{Email address:}

xiewei0690@163.com

\section{To cite this article:}

Wang Ting. Research on the Transformation of Service Capability of University Libraries in the Background of "Double First-Class" Construction. Science Innovation. Vol. 6, No. 2, 2018, pp. 87-91. doi: 10.11648/j.si.20180602.16

Received: April 20, 2018; Accepted: June 6, 2018; Published: June 22, 2018

\begin{abstract}
Double First-Class" construction is the long-term guiding construction program proposed by the education department of China after the deployment of the "Project 985" and "Project 211" strategic plans to guide the development of China's higher education. As one of the functional departments of colleges and universities, university libraries need to comprehensively examine the challenges faced by the transformation of their own service capabilities in the context of "Double First-Class" construction. Based on this, we will clarify the main direction of transformation and development in serving college personnel training, discipline construction, and document resource supply, in order to better serve our school's "Double First-Class" construction.
\end{abstract}

Keywords: "Double First-Class" Construction, University Library, Service Capability, Transformation

\section{“双一流”建设背景下高校图书馆服务能力转型研究}

\section{王婷}

思想政治教育研究中心, 东北师范大学, 长春市, 中国

邮箱

xiewei0690@163.com

摘要：“双一流”建设是中国教育部门在部署“985工程”和“211工程”战略规划之后, 为指导中国高等教育的发展方向 而提出的长期指导性建设纲领。高校图书馆作为高校职能部门之一, 有必要全面审视“双一流”建设背景下自身服务能 力转型面临的挑战, 并以此为基础, 明确在服务于高校人才培养、学科建设、文献资源供给等方面转型发展的主攻方 向, 以期更好的服务于本校“双一流”建设。

关键词: “双一流”建设, 高校图书馆, 服务能力, 转型

\section{1. 引言}

“双一流”建设目标提出以来, 中国各高校纷纷响应“双 一流” 建设的号召, 进一步提出了自身总体建设和学科建设 的方向, 力求在新一轮的高等教育发展过程中能够主动适应
时代发展环境, 获得突破式的创新发展 $[1]$ 。在高校图书馆 服务高校发展的总体指导思想下, 高校图书馆作为高校科研 活动的支持部门之一，应当主动适应高等教育改革发展的方 向, 在 “双一流” 建设框架下, 结合自身建设实际, 加快推 进自身服务能力的转型发展, 为服务对象提供更为优质的服 
务内容和服务环境 [2]。从当前高校图书馆适应 “双一流” 建设目标的实际情况来看, 大部分高校图书馆还未形成实质 性的服务能力转型升级方案, 这在一定程度上阻碍了高校图 书馆服务于本校 “双一流” 建设的进度。因此, 高校图书馆 有必要全面审视 “双一流” 建设背景下自身服务能力转型所 面临的挑战, 并以此为基础, 进一步探索在人才培养、学科 建设、文献资源供给等方面转型发展的具体路径, 以期更好 的服务于本校 “双一流” 建设。

\section{2. “双一流” 建设背景}

“双一流” 作为中国教育历史上做出的重大战略决策于 2017年被中国政府多部门联合颁布, 其含义是指世界一流大 学和世界一流学科。开展 “双一流” 建设的主要目标是将中 国质量较高的部分大学及部分大学的优势学科纳入到世界 一流行列当中。世界一流大学建设与世界一流学科建设并非 割裂而发展, 两者之间存在着一定的必然联系, 其中一流学 科建设是实现一流大学建设的前提和基础, 而一流大学建设 目标的实现必将会对一流学科的建设起到引领和示范作用。 目前, 世界一流大学与世界一流学科在国际范围内还未形成 统一的认定标准, 但这并不影响“双一流”建设目标的实现, 通常情况下, 可以从宏观方面判定, 高校在世界高校排名中 名列 100 名之内就可看作是实现了建设 “世界一流大学” 的 目标, 同理, 高校学科在世界学科排名名列100名之内就可 看作是实现了建设 “世界一流学科”的目标 [3]。

“双一流”建设是中国高等教育在部署 “985工程” 和 “211工程” 战略规划之后, 为进一步适应中国全面建 设社会主义现代化国家的新征程而提出的长期指导性建 设纲领。早期 “985工程” 和 “211工程” 提出的目的在于 通过工程的实施, 来确保高等教育建设资金的合理使用, 并逐步缩小与世界一流大学的差距。但近年来这两大工程 实施过程中的缺点逐步暴露出来, 其中最大的缺点在于工 程长期处于封闭运行状态, 一些具有优势学科的高校由于 总体实力不强而难以进入这些工程行列 [4]。而 “双一流” 建设则系统性的提出了世界一流大学建设与世界一流学 科两大战略目标, 并突出强调了学科建设在实现总体目标 过程中的基础性地位, 从而使一批具备优势学科的高校也 成为了 “双一流” 建设的重点支持对象。自2017年以来, 中国政府的相关部门联合出台了关于推进世界一流大学 和一流学科建设实施等系列文件, 这充分说明了中国高校 “双一流”建设目前已进入实施性阶段 [5]。据教育部有 关新闻报道，其它关于支持 “双一流” 建设的配套性文件 也将于今后一段时期陆续出台实施。

\section{3. “双一流”建设背景下高校图书馆服务能力 转型面临的挑战}

\section{1. 高校图书馆的服务角色发生转变}

以往高校图书馆服务的主要职能在于通过文献资料 的供给来为本校用户提供各种类型的信息服务。在当前 “双一流”建设的背景环境下, 高校图书馆的服务角色将 发生重要转变, 主要体现在以下三个方面 [6]:
一是高校图书馆的服务方向必须有所拓展。随着中国 社会的不断发展进步, 高校图书馆各类用户群体对信息资 源的需求更加复杂化和多元化, 同时要求图书馆必须以更 为便捷和先进的技术进行信息情报服务。要求高校图书馆 必须加强类似于云计算、大数据等高新技术的运用, 并对 信息资源进行深层次的加工和整理, 从而能够进一步满足 用户的需求。

二是图书馆馆员的工作能力必须适应 “双一流” 建设 背景下学科建设的要求。在传统的馆员职能范围中, 馆员 的主要职责在于进行信息资源的管理和单向的传送。随着 “双一流”建设目标的提出, 高校学科水平的发展被赋予 了新的内涵, 其中就包括了学科参考咨询服务的发展。要 求图书馆必须配置能够专项从事学科服务的馆员, 并且能 够有效的协助高校学科建设团队进行学科建设的服务。

三是高校图书馆馆藏资源供给必须适应 “双一流” 建 设的要求。在互联网和数字化时代, 数字化馆藏资源的价 值进一步得到挖掘, 高校图书馆馆馆藏资源供给的评价标 准不再以数量的多少来进行评定。馆藏资源结构配给状况、 馆藏资源与学科建设的匹配程度、馆藏资源的共享共用状 况都将直接影响到高校图书馆馆藏资源的服务于 “双一流” 建设的供给水平。

\section{2. 高校图书馆发展理念面临的挑战}

目前, “双一流”建设仅对高校学科建设提出了总体的 要求, 但是各个高校优势学科的方向各不相同, 如何使高校 学科的发展符合世界一流学科的建设要求, 必须视高校学科 发展的具体情况来定。这就意味着高校必须全面衡量优势学 科发展的基础条件, 提出科学合理的发展思路。高校图书馆 作为支持高校学科发展的重要职能部门, 也应当根据高校学 科发展的宏观规划, 进一步明确自身支持学科建设的基础理 念, 并将这一理念贯彻落实到实际的行动方案当中 [7]。

首先, 高校图书馆的人力、物力、财力是一定的, 如 何高效的配置这些有限的人力、物力、财力, 从而使这些 基础性资源在 “双一流” 建设目标下，得到最大程度的发 挥, 是高校图书馆服务转型升级所要考虑的首要问题。特 别是在共享共用的时代理念下, 高校图书馆应当进一步推 动与其它社会部门在资源开发方面共享共用的程度, 从而 更好的服务于高校优势学科的建设。

其次, 高校图书馆要树立动态发展的理念, 由于中国 有关 “双一流” 建设方案的提出距今只有两年的时间, 各 方面的配套政策还未完全出台实施, 理论研究的成果, 特 别是关于高校图书馆支持 “双一流” 建设的研究成果还未 形成有效的智慧支撑体系。因此, 高校图书馆必须以相关 政策导向和学术研究成果为依据, 在形成总体发展目标的 同时, 构筑动态发展工作机制, 不断调整发展的具体路径, 以此来推动建设成果的不断涌现。

\section{4. “双一流”建设背景下高校图书馆服务能力 转型的基本导向}

从当前高校图书馆支持 “双一流” 建设的工作实质情 况来看, 关于服务能力转型的基本导向尚未取得统一的认 
识。如何确定服务能力转型的针对对象? 如何主导服务能 力转型? 怎样评价服务能力转型的成果? 都值得中国高 校图书馆的深刻分析。随着 “双一流” 建设指导性配套 政策的逐步出台和实施, 结合中国高等教育的总体发展理 念以及图书情报事业发展的基本趋势, 高校图书馆应当进 一步认清服务能力转型的基本导向。其中最为核心的就是 明确服务对象、培育服务动能、拓展服务技术手段。

\section{1. 明确学科建设团队为服务的主要对象}

在实际构建世界一流大学的过程中, 一流学科的建设 是至关重要的。目前, 判断一流学科的标准, 除了学科的 竞争力和师资实力之外, 还包括教育发展水平和总体科研 水平等。其中总体科研水平是以学科建设团队人员为核心 导向, 并将科研的最终成果作为衡量的重要标准。学科建 设团队人员从事科学研究的过程, 也是科研成果不断累积 的过程。因此, 高校图书馆必须根据学科服务对象的需要, 结合科研人员的工作情况, 促使服务内容更好的融入于科 研成果的每一个研发环节中, 同时将自身的服务理念与科 研团队充分融合, 从而促进服务的学科建设团队研发水平 进一步提升, 进而增强高校优势学科的影响力。

\section{2. 以提升馆员的学科服务能力作为培育服务动能的主 要目标}

现阶段, 满足学科建设团队对信息情报的需求已成为 大部分高校图书馆的核心任务。在实际开展工作的进程中, 学科馆员也普遍将提供资源以及基础性服务作为主要的 工作 $[8]$ 。然而, 要想促使本校一流学科更好的发展, 高 校图书馆就必须重视学科馆员的培养, 突破现有格局的限 制, 进一步促进学科馆员价值的发挥 $[8]$ 。从服务内容方面 来讲, 学科馆员可以加强与优势学科建设团队的交流与互 动, 构建相应的联络机制, 并将工作的重点倾向于资源的 构建、信息的整合以及科研的动态追踪等方面。从服务深 度方面来讲, 学科馆员不仅要提供基础性服务, 而且还要 针对优势学科当前的研究内容, 为研究的每一个环节提供 具有实质性的服务。从服务责任方面来讲, 高校图书馆应 该进一步构建科学合理的量化考核机制, 以多方协作的方 式开展对学科馆员服务的评价, 目的在于提高考核的公平 性和准确性, 并建立起一个将客观事实数据作为主要依据, 更为科学、合理的考核体系。通过主观和客观两个评价类 型的有机结合, 多方协作的评估结果就可以更为科学的衡 量出学科馆员的工作绩效, 而且还可以确保服务工作责任 制的充分发挥。

\section{3. 以嵌入式学科服务能力拓展服务技术手段}

为实现支持学科建设团队推动本校优势学科发展的 基本目标, 高校图书馆应进一步强化服务模式总体规划设 计。目前，“嵌入式” 服务系统已成为大部分高校图书馆 开展学科服务的重要工具。该项服务系统在设计时, 需要 注意以下三方面的问题 [9]：（1）针对学科导航只能在一 定范围内进行信息的搜索以及对信息需求的挖掘深度还 远远不够的情况, 可考虑建设一键式文献资源搜索系统; (2) 服务系统的设计应当充分考虑学科服务馆员的工作
实际和用户的基本诉求。一方面, 要满足学科服务馆员便 捷化进行文献信息资源推广的实际情况, 另一方面, 要满 足用户拥有个性化学术主页、互动式沟通渠道的基本诉求; （3）服务系统应以 “支持线下服务拓展, 强化线上服务 功能” 为目标, 积极建设学科服务空间, 从而使学科服务 馆员能够即时关注科研团队的最新研究进展, 并以主动服 务的方式来为科研团队提供信息资源保障, 助力研究过程 中各类问题的及时解决。

\section{5. “双一流”建设背景下高校图书馆服务能力 转型的基本保障}

图书馆作为高校的重要职能部门, 其学科支撑作用的 发挥必须紧随高校学科发展的宏观战略规划, 并在机构运 行方面逐步适应高校学科建设的管理机制。因此, 高校图 书馆要想确保在 “双一流” 建设背景下实现服务能力的转 型, 就必须在组织结构、决策机制、联动评价机制上有深 层次的转变。

\section{1. 组织机构保障}

目前, 国内外高校图书馆在服务学科建设的过程中, 其组织形式更加多元化。例如, 美国斯坦福大学胡佛研究 所, 其组织形式主要是工作小组为主。工作小组普遍采用 领导负责制, 依照自愿原则, 自行招募研究成员, 共同对 感兴趣的课题进行研究。所招募的研究人员并没有身份的 限制, 既可以是本校教师, 也可以是优秀的在读研究生, 还可以是校外专家 $[10]$ 。受此启发, 中国高校图书馆在推 进学科服务的过程中, 应当进一步完善学科馆员嵌入学科 建设团队的组织形式, 在遵从学科建设团队研究主体作用 的前提下, 进一步完善学科馆员嵌入学科建设团队的组织 形式, 推动学科馆员以服务者、研究者、教学者等多元化 身份参与到一流学科的建设当中, 从而使得学科团队的组 织方式更具有广域的灵活性。这也符合当下所学科团队建 设所提倡的 “学科馆员+高校教师+研究生” 模式 [11]。

\section{2. 决策机制保障}

为了从服务机制设计方面, 给予高校图书馆服务学科 建设强有力的保障, 就必须对 “谋” 和 “断” 进行重点研 究, 构建能谋善断的合理的决策服务框架, 重视服务的开 放性和公平性, 以 “旋转门” 机制为突破方向, 促使研究 者和决策者的有效转换。“旋转门” 机制就是任职期满的 政府官员加入到学科建设团队, 通过参与相关政策的分析 和研究, 来为学科的发展提供政策指导智囊服务 [12]。实 质上, “旋转门” 机制在中国已有一定的实践基础, 具体 体现在2000年至2005年期间, 中国教育部曾鼓励高校学者 以挂职或者调职的形式，加入中国政府机构，并担任相关 职务, 来制定高校发展尤其是学科发展的相应政策法规。 受此启发, 高校图书馆应当研习 “旋转门” 制度建立和 应用的基础, 积极与上级主管部门联络, 从图书馆情报事 业管理规划的角度, 邀请上级业务主管领导参与到高校优 势学科建设的过程中, 从而使高校能够获得包括资金和优 惠政策在内的各种政策性支持。 


\section{3. 联动评价机制保障}

目前, 中国高校图书馆虽然加快了馆内学科馆员的发 展力度, 并形成了与优势学科的有效匹配, 但普遍缺乏对 学科馆员有效的评价体系, 不仅学科馆员的工作成效难以 准确衡量, 而且难以激发学科馆员的工作积极性。因此, 建立科学合理的学科馆员评价体系已成为推动学科馆员 制度实施的关键。目前, 联动评价机制已成为学术界针对 学科馆员评价的新动向。联动评价机制的优势在于, 能够 在学科建设的项目申报、论文发表、科技成果转移转化、 本科教学评估等诸多环节当中, 恰当的体现出学科馆员服 务内容、服务效果、服务时效性的具体评价指标, 并能够 着重体现学科建设决策的主体思想。这不仅使学科建设的 各个环节与学科馆员的服务形成了有效的联动, 而且使每 位学科建设的相关者都能切实的体会到学科馆员服务的 效果。高校应当依据联动评价机制的基本工作原理, 结合 本校学科建设开展的实际, 在实现学科馆员评价指标融入 学科建设环节的基础上, 进一步优化评价工作的开展方式, 使得学科馆员评价指标体系更加切合一流学科建设的目 标。

\section{6. “双一流”建设背景下高校图书馆服务能力 转型的路径}

\section{1. 深化学科服务评价改革, 靶向定位学科服务}

在高校以往的学科服务过程中, 通常过分关注于所提 供的文献资源的数量及档次, 而对文献内容的价值没有充 分的衡量和把握。这种方式难以综合性的分析该研究发展 在学术广度和深度方面的详细情况, 更无法很好的预估该 研究领域未来的发展趋势, 致使教师和科研团队的研究效 率难以有效的提升 [13]。因此, 高校图书馆应该以靶向定 位为目标, 通过精准化的学科服务, 来满足教师和科研团 队的个性化需要, 保证其可以实时的了解研究领域的发展 趋势, 提高其估量科研能力以及付出的科学性和精准度, 从而为下一步的科研提供帮助。需要注意的是, 精准学科 服务除了包括研究领域竞争分析和团队科研能力分析之 外, 还涉及到投稿期刊指导以及研究热点和趋势分析等。

\section{2. 以产学研结合为导向, 深入挖掘知识情报服务价值}

随着知识情报服务重要性的逐渐凸显, 部分高校图书 馆的认识也在逐渐加深, 并提高了资源的倾斜力度。以上 海海事大学图书馆为例, 该图书馆结合海事专业特色和海 事行业发展趋势, 对知识情报服务模式进行了优化改革, 不仅形成了新型的情报服务模式，而且给予了服务对象更 高水平的知识情报服务。由此可见, 高校图书馆必须根据 地区行业和企业用户的实际需要, 对自身资源优势进行深 入的挖掘, 不断拓展服务内容, 创新服务方式。比如, 针 对应用性研究, 可以通过开展信息检索和分析服务, 来满 足学科建设团队立项论证的需要; 针对科研成果的转化转 移环节, 可以通过系统性的分析科技成果应用发展的内在 规律, 来促进学科团队研究成果进一步转化 [14]。上述
服务内容不仅能够提升建设团队的总体研究价值, 而且还 有助于提高科学技术对经济发展的贡献程度。

\section{3. 紧扣教学实践环节, 强化学生信息素养的培育}

信息时代，“双一流”的建设必定会对高校学生的信 息素养提出一定的要求, 这就意味着高校图书馆可以通过 强化对高校学生的信息素养培育, 来实现对高校“双一流” 建设的支持。公开课以及选修课作为现阶段高校推行信息 素养教育的主要方式, 使得高校图书馆无法真正的了解学 生的需求, 更难以取得良好的教育效果。所以, 高校图书 馆要想进一步发挥对高校学生信息素养的培育作用, 必须 要将服务的学生进行细致化的分类划归, 提供个性化的服 务 [15]。由于没有参加过信息素质方面的教育以及培训, 且对图书馆服务的内容及流程过于模糊, 低年级学生普遍 存在不能有效的利用图书馆开展学习的问题。针对其状况, 高校图书馆可以主动与低年级学生进行沟通, 帮助其了解 馆藏资源检索和数字资源检索等服务, 明确馆藏的具体分 布, 同时激发他们对信息检索的兴趣, 进而为其将来的研 究式学习奠定基础。与此相对, 由于对图书馆的服务方式 具备一定的实践能力, 高年级学生以及研究生的信息素养 培训目标往往更高。在这种情况下, 高校图书馆除了要推 广信息检索方法之外, 还必须对情报检索语言以及使用频 率较高的文献管理软件等内容形成详细的培养方案。

\section{4. 兼顾文献资源建设的全面性, 形成特色学科文献资 源保障体系}

学科文献资源建设不仅能够推动学校科研工作进一 步的发展, 保证工作的持续性, 而且和高校图书馆的未来 息息相关, 其建设的水平更是决定着服务转型升级的质量 和效率。为了切实发挥图书馆服务学科的效用, 必须在兼 顾其他学科文献的同时, 着重对特色学科文献资源进行收 藏、保护和构建, 形成特色学科文献资源保障体系。同时, 从数量以及质量的角度进行认真的谋划, 促使资源结构更 加的均衡, 实现学科馆藏体系的优化升级 [16]。同时, 图 书馆必须针对学科服务对象的实际需要, 有计划的进行资 源的收集和整合, 从而构建起具备鲜明特色且体系完善的 资源数据库。另外, 还要对包括评述、文摘、综述以及索 引在内的二次文献, 积极的开展数据库建设, 以提升资源 的利用效率。

\section{7. 结论}

高校图书馆作为高校的优势资源和教育职能部门之 一, 必须全面审视 “双一流” 建设背景下自身服务能力转 型所面临的挑战。明晰此背景下, 把握好高校图书馆服务 能力转型的三个核心基本导向的同时, 紧随高校学科发展 的宏观规划, 以组织结构、决策机制、联动评价机制三方 面共同作用, 运用精准的实践路径致力于服务能力转型, 保障高校图书馆服务能力实现深层次高水平的转变, 以期 更好的服务于高校 “双一流” 建设工程, 从而不断实现中 国教育事业的创新式发展。 


\section{参考文献}

［1］王钱永，任丽清. “双一流”建设视角下地方高校区域创新 能力建设 $[J]$. 中国高教研究, 2016(10) : 38-42。

２］王婧怡，石宏伟，袁润。“双一流”大学建设下的高校图书 馆学科馆员制现状及建设策略 $[\mathrm{J}]$. 图书馆理论与实践, 2017 (06) : 38-40。

［3］徐岗. “双一流” 建设背景下图书馆信息资源建设的优化路 径 $[J]$. 黄山学院学报, 2017 (04): 137-141。

４4］周玉清, 黄欢, 付鸿飞. 以 “双一流” 建设引领研究生教育 的改革与发展一一 “双一流” 建设高端论坛综述 [J]. 研究 生教育研究, 2016(03):1-6。

[5] 国务院. 国务院关于印发统筹推进世界一流大学和一流学 科建设总体方案的通知 [EB/OL]. [2017-03-20]。

６］邹双红, 周炫, 向艳. 双创与双一流建设下的图书馆服务 变革 $[J]$. 贵图学苑, 2017 (02) :27-31。

[7] 刘明昕. 高校图书馆学科服务的创新工作研究 [J]. 科技创 新导报，2016，(27) : 175-176。
［8］涂文菠. “双一流”政策下的国内高校图书馆学科服务探讨 [J]. 大学图书情报学刊, 2017 (5) :62-66。

[9] 初景利, 孔青青, 橸冠楠. 嵌入式学科服务研究进展 [J]. 图书情报工作，2013(22):11-17。

[10] 吴育良. 从胡佛研究所的转型谈地方社科院图书馆在智库 中的新定位 $[\mathrm{J}]$. 新世纪图书馆, 2012 (11) : 83-85。

[11] 张明, 张䒯, 李艳国. 高校图书馆智库的组织架构及职能定 位研究 $[J]$. 图书馆工作与研究, 2016 (4) : 12-13。

[12] 李占峰, 金家厚, 鲍宗豪. 中国智库发展亟需理念和制度创 新 [J]. 开放导报, 2011(6): 100-104。

[13] 徐健晖. “双一流” 建设背景下高校图书馆学科服务创新研 究 $[J]$. 大学图书情报学刊, 2017 (02):55-58。

[14] 柴会明, 张立彬, 李易航. 国内图书馆知识产权相关问题研 究述评 $[J]$. 图书馆, 2017 (10) : 70-77。

[15] 李苹, 李纪. 分层、多阶、个性化的学科服务体系构建 [J]. 图书馆学研究, 2012（19）:64-67。

[16] 张小梅, 郭风媛. 高校图书馆为重点学科建设的文献保障与 服务 $[J]$. 中华医学图书情报杂志，2009（04）:45-47。 